\title{
Effect of local infiltration analgesia, peripheral nerve blocks, general and spinal anesthesia on early functional recovery and pain control in total knee arthroplasty
}

\author{
M. T. Berninger ${ }^{1,2^{*}}$ (D) J. Friederichs ${ }^{2}$, W. Leidinger ${ }^{3}$, P. Augat ${ }^{4,5}$, V. Bühren ${ }^{2}$, C. Fulghum ${ }^{1}$ and W. Reng ${ }^{1}$
}

\begin{abstract}
Background: Postoperative pain control and enhanced mobilization, muscle strength and range of motion following total knee arthroplasty (TKA) are pivotal requisites to optimize rehabilitation and early recovery. The aim of the study was to analyze the effect of local infiltration analgesia (LIA), peripheral nerve blocks, general and spinal anesthesia on early functional recovery and pain control in primary total knee arthroplasty.

Methods: Between January 2016 until August 2016, 280 patients underwent primary TKA and were subdivided into four groups according to their concomitant pain and anesthetic procedure with catheter-based techniques of femoral and sciatic nerve block (group GA\&FNB, $n=81$ ) or epidural catheter (group SP\&EPI, $n=51$ ) in combination with general anesthesia or spinal anesthesia, respectively, and LIA combined with general anesthesia (group GA\&LIA, $n=86$ ) or spinal anesthesia (group SP\&LIA, $n=61$ ). Outcome parameters focused on the evaluation of pain (NRS scores), mobilization, muscle strength and range of motion up to 7 days postoperatively. The cumulative consumption of (rescue) pain medication was analyzed.

Results: Pain relief was similar in all groups, while the use of opioid medication was significantly lower (up to 58\%) in combination with spinal anesthesia, especially in SP\&EPI. The LIA groups, in contrast, revealed significant higher mobilization (up to 26\%) and muscle strength (up to 20\%) in the early postoperative period. No analgesic technique-related or surgery-related complications occurred within the first 7 days. Due to insufficient pain relief, 8. $4 \%$ of the patients in the catheter-based groups and $12.2 \%$ in the LIA groups resulted in a change of the anesthetics pain management.

Conclusions: The LIA technique offers a safe and effective treatment option concerning early functional recovery and pain control in TKA. Significant advantages were shown for mobilization and muscle strength in the early postoperative period while pain relief was comparable within the groups.
\end{abstract}

Keywords: Local infiltration analgesia, Femoral nerve block, Total knee arthroplasty, Epidural catheter, General anesthesia, Spinal anesthesia

\footnotetext{
* Correspondence: Markus.Berninger@bgu-murnau.de

${ }^{1}$ endogap, Joint Replacement Institute, Garmisch-Partenkirchen Medical

Center, Auenstr. 6, 82467 Garmisch-Partenkirchen, Germany

${ }^{2}$ Department of Trauma Surgery, BG Trauma Center Murnau, Prof.-Küntscher

Str. 8, 82418 Murnau, Germany

Full list of author information is available at the end of the article
}

(c) The Author(s). 2018 Open Access This article is distributed under the terms of the Creative Commons Attribution 4.0 International License (http://creativecommons.org/licenses/by/4.0/), which permits unrestricted use, distribution, and reproduction in any medium, provided you give appropriate credit to the original author(s) and the source, provide a link to the Creative Commons license, and indicate if changes were made. The Creative Commons Public Domain Dedication waiver (http://creativecommons.org/publicdomain/zero/1.0/) applies to the data made available in this article, unless otherwise stated. 


\section{Background}

Postoperative pain after total knee arthroplasty (TKA) is still a challenging issue. For a successful outcome, pain control following TKA is essential to achieve early mobilization, good functional outcome, optimal rehabilitation and enhanced recovery [1]. Therefore, the primary goals of peri- and postoperative analgesic treatment are to reduce pain and immobilization and to minimize opioid requirements and opioid-related adverse events. Enhancing these outcomes has a potential beneficial influence on patient morbidity and satisfaction, the degree of required postoperative care, as well as economic perspectives.

There is a considerable debate on the optimal form of postoperative analgesia in total knee replacement [2]. Several peri- and postoperative pain control strategies have been established in the last years including peripheral nerve blocks, epidural analgesia as well as local infiltration analgesia (LIA) and (systemic) opioids [1].

Regional anesthesia techniques are widely used to deliver intraoperative analgesia and to minimize postoperative pain after TKA [1, 3]. In general, femoral nerve blocks (FNB) are the preferred method for postoperative pain reduction by blocking the femoral nerve, the lateral femoral cutaneous nerve and branches of the obturator nerve; however, pain - especially in the popliteal space may not be completely under control [4]. Therefore, the combination of FNB with a sciatic nerve block (SNB) seems to be a suitable option to optimize pain management $[5,6]$. In terms of pain control, epidural anesthesia in knee surgery did not show any advantages compared to regional analgesia such as FNB [3]. However, it may result in a higher side-effect profile including severe neuraxial complication compared to $\operatorname{FNB}[7,8]$.

As an alternative method for postoperative pain control after TKA, LIA around the soft tissues of replaced knee joints was introduced by Kerr and Kohan in 2008 with an increasing interest in recent years [9]. The analgesic agents are intraoperatively administered by the surgeon to block pain conduction directly. Thereby, systemic side effects associated with postoperative analgesics as well as additional invasive procedures (e.g. administration of analgesic catheters) for pain management are minimized. Moreover, compared to peripheral nerve blockades LIA lacks the possible disadvantage of motor impairment and quadriceps weakness, the risk of nerve injury or limitation of patient ability to ambulate in the immediate postoperative period [10].

Several studies successfully demonstrated significant pain relief and reduced opioid requirements in the early postoperative period by use of LIA compared to placebo [11-13] or (peripheral) analgesic catheters [14, 15]. Data comparing LIA with continuous epidural analgesia are limited and favor LIA over continuous epidural analgesia, particularly due to the side effects and early mobilization [16-18]. The comparability of the results of previous trials is, however, restricted by different anesthesia procedures (general versus spinal anesthesia) and systemic pain medication.

In literature, there is no study analyzing the effect of LIA, (peripheral) catheter-based techniques and their combination with general or spinal anesthesia in one patient collective on pain control, mobilization, muscle strength and range of motion for up to 7 days postoperatively. The hypothesis of this study was that each anesthetic procedure directly influences the immediate postoperative status of the patient in terms of pain control, mobilization, muscle strength and range of motion. Therefore, the aim of the study was to analyze the effect of femoral nerve block and general anesthesia (group GA\&FNB), epidural catheter and spinal anesthesia (group SP\&EPI), LIA combined with general anesthesia (group GA\&LIA) and spinal anesthesia (group SP\&LIA), respectively, on early functional recovery and pain control in primary TKA.

\section{Methods \\ Patients}

During the period from January 2016 until August 2016, 300 patients underwent primary TKA in a single center for alloplasty. Finally, a total of 280 patients were eligible for the study having received general or spinal anesthesia in combination with a FNB, epidural catheter or LIA. The inclusion criterion was primary TKA for osteoarthritis. Patients were excluded if they had a primary constrained prosthesis, secondary arthritis due to rheumatoid arthritis or trauma, osteonecrosis or revision surgery. This study was performed in conformity with the Declaration of Helsinki and was approved by the Ethics Committee of the Bavarian State Chamber of Physicians (ID: 2017-109). Patient demographics, surgery details, and clinical data are shown in Table 1. Pain medication and use of opioids prior to the surgery in daily life were elaborated from the patients' medical history.

Patients were retrospectively divided into 4 groups according to their received anesthetic and peri-and postoperative analgesic procedure as follows:

Group GA\&FNB: General anesthesia + FNB/SNB $n=81$.

Group SP\&EPI: Spinal anesthesia + epidural catheter $n=51$.

Group GA\&LIA: General anesthesia + LIA $n=86$.

Group SP\&LIA: Spinal anesthesia + LIA $n=61$.

\section{Anesthetic techniques}

After induction of general anesthesia, patients allocated to GA\&FNB had a FNB catheter inserted with real-time monitored ultrasound imaging. A total of $20 \mathrm{ml}$ of $0.1 \%$ ropivacaine was injected around the femoral nerve; 
Table 1 Patients demographics and clinical data

\begin{tabular}{|c|c|c|c|c|}
\hline & GA\&FNB & SP\&EPI & GA\&LIA & SP\&LIA \\
\hline Patients & $n=82$ & $n=51$ & $n=86$ & $n=61$ \\
\hline Gender & $f=48 ; m=34$ & $f=31 ; m=20$ & $f=52 ; m=34$ & $f=38 ; m=23$ \\
\hline Age & $67 \pm 11.4$ & $71 \pm 9.3$ & $68 \pm 10.2$ & $70 \pm 9.0$ \\
\hline Chronic pain patient & $\mathrm{n}=5(6.1 \%)$ with opioid: $n=2$ & $\mathrm{n}=2(3.9 \%)$ with opioid: $n=1$ & $\mathrm{n}=5(5.8 \%)$ with opioid: $n=3$ & $\mathrm{n}=2(3.3 \%)$ with opioid: $\mathrm{n}=1$ \\
\hline \multirow[t]{3}{*}{ Piritramide } & OP: $n=34$ (41.4\%): $10.0 \mathrm{mg} \pm 5.4$ & OP: $\mathrm{n}=6$ (11.8\%): $6.9 \mathrm{mg} \pm 1.9$ & OP: $n=53$ (61.6\%): $9.9 \mathrm{mg} \pm 4.4$ & OP: $n=6$ (10.0\%): $7.5 \mathrm{mg} \pm 0.0$ \\
\hline & Day $1: n=7$ (8.5\%): $8.6 \mathrm{mg} \pm 2.8$ & Day 1: $\mathrm{n}=1$ (2.0\%): $7.5 \mathrm{mg} \pm 0.0$ & Day 1: $n=6$ (7.0\%): $9.0 \mathrm{mg} \pm 3.7$ & Day 1: $\mathrm{n}=6(10.0 \%): 8.8 \mathrm{mg} \pm 3.1$ \\
\hline & Day 2: $\mathrm{n}=2$ (2.4\%): $7.5 \mathrm{mg} \pm 0.0$ & Day 2: $\mathrm{n}=1$ (2.0\%): $7.5 \mathrm{mg} \pm 0.0$ & Day 2: $\mathrm{n}=1$ (1.2\%): $9.0 \mathrm{mg} \pm 3.7$ & Day 2: $n=2$ (3.3\%): $10.8 \mathrm{mg} \pm 4.6$ \\
\hline Salvage pain management & $\begin{array}{l}n=4(4.9 \%) \\
\rightarrow P C I A: n=4\end{array}$ & $\begin{array}{l}n=7(13.7 \%) \\
\rightarrow P C I A: n=1 \\
\rightarrow 3 i n 1: n=6\end{array}$ & $\begin{array}{l}n=9(10.5 \%) \\
\rightarrow 3 i n 1: n=9\end{array}$ & $\begin{array}{l}n=9(14.8 \%) \\
\rightarrow 3 i n 1: n=8 \\
\rightarrow P C I A: n=4\end{array}$ \\
\hline LIA & - & - & $160 \mathrm{ml}$ & $160 \mathrm{ml}$ \\
\hline Dexamethasone & - & - & $16.4 \mathrm{mg} \pm 3.1$ & $15.7 \mathrm{mg} \pm 3.1$ \\
\hline
\end{tabular}

additionally ultrasound-guided sciatic nerve block with $20 \mathrm{ml}$ of $0.1 \%$ ropivacaine was established as single shot block. Postoperatively, $0.2 \%$ ropivacaine was continuously infused at the rate of $3 \mathrm{ml} / \mathrm{h}$ for 3 days through the femoral catheter.

In SP\&EPI, a catheter was preoperatively sited at the cranial lumbar vertebrae combined with a spinal anesthesia ( $1 \mathrm{ml}$ of $0.5 \%$ bupivacaine and $10 \mu \mathrm{g}$ sufentanil in the subarachnoid space) in a single needle technique. After recovery from spinal anesthesia under the level L3, an initial $10 \mathrm{ml}$ bolus containing 0.5\% bupivacaine, $0.6 \mu \mathrm{g} / \mathrm{ml}$ sufentanil and saline was introduced. Thereafter, patients were self-medicated with a bolus of $4 \mathrm{ml}$ via a patient-controlled epidural anesthesia (PCEA) system with a lockout of 20 min. PCEA was discontinued three days after surgery.

\section{Local infiltration anesthesia (LIA)}

For the patients in the LIA groups, the surgeons undertook periarticular injection of local anesthetic during surgery. The injection technique used was similar to the technique described by Kerr and Kohan [9]. However, the infiltration used in this study only consisted of $160 \mathrm{ml}$ of $0.2 \%$ ropivacaine without any additional components. At the beginning of the anesthesia, dexamethasone $(0,2 \mathrm{mg} / \mathrm{kg}$ body weight $)$ was injected intravenously. All infiltration was done using $25-\mathrm{ml}$ syringes and $10-\mathrm{cm}$-long $19-\mathrm{G}$ spinal needles. The LIA solution was administered after completion of all femoral and tibial osteotomy steps, immediately before cement fixation of the tibial component. The LIA solution was systematically injected into the tissues around the knee joint according to a standardized protocol: in the medial and lateral tibial and femoral periosteum as well as medial and lateral posterior articular capsule, and in the subcutaneous tissue, in the Hoffa fat pad and finally intraarticularly after capsular suture.

\section{Surgery}

All surgeries were performed by three senior surgeons. Intraoperatively, single-shot cefazolin $2 \mathrm{~g}$ (or clindamycin $600 \mathrm{mg}$ in case of incompatibility of penicillin) for infection prophylaxis was given to all patients. The surgeries were performed with a standard midline vertical incision and medial parapatellar approach. A tourniquet was inflated to $250 \mathrm{mmHg}$ at the beginning of the surgery and deflated after removal of the surgical dressings. In all cases, the $\mathrm{LCS}^{\bullet}$ complete Knee System (DePuy Synthes, Warsaw, IN, USA) was used; the tibial component was fixed with cement. Bone resections and implant insertion were conducted according to the manufacturers manual. The patella was generally not resurfaced; however, patella osteophytes were removed and circular patella denervation was regularly performed.

\section{Postoperative pain management and care}

Postoperative management was identical in all groups. After surgery, every patient was given peripheral pain medication (WHO grade I, e.g. paracetamol, metamizole, ibuprofen or diclofenac) for about 2 weeks to relieve pain and low molecular weight heparins subcutaneously for about 2 weeks to prevent deep vein thrombosis. The cumulative doses of rescue analgesia (hydromorphone p.o. or piritramide i.v.) were also registered.

Postoperative physiotherapy was started immediately after surgery in a progressive manner and continued daily. A specially trained pain service regularly visited all patients twice a day for the first four postoperative days.

\section{Outcome measures}

Self-reported pain scores in terms of numeric rating scores (NRS) at rest and with activity $(0=$ no pain; $10=$ worst pain) from day of surgery until postoperative day 4 were collected and analyzed. For evaluation of functional outcomes, grade of mobilization ranging from values of 1 to 6 according to our institutional grading 
system of mobilization was analyzed: $1=$ bedridden, $2=$ sitting, $3=$ standing, $4=$ walking in room, $5=$ walking on the floor, $6=$ walking stairs. Furthermore, muscle strength according to the British medical research council (M0/5-M5/5) and passive range of motion (degrees of extension and flexion) were examined. Functional outcomes of mobilization, muscle strength and range of motion were documented daily from pre-operative day until postoperative day 7 , respectively. The patients' medical files were also studied for potential analgesic technique-related or surgery-related complications within the first 7 days, such as rates of neurologic events, cardiovascular events, falls, knee joint infections, prosthesis loosening, or revision surgery. All data were collected from the patients' medical records and nurses' observational charts.

\section{Data analysis}

Statistical analysis was performed with SPSS statistical software 20.0 (SPSS for Windows, ver. 20.0; SPSS, Chicago, IL, USA). Descriptive statistics were calculated for all variables of interest. Continuous measures such as age were summarized using means and standard deviations whereas categorical measures were summarized using counts and percentages.

The Kruskal-Wallis test was used for analysis of one nominal variable and one ranked variable. In a further detailed analysis, post-hoc comparisons of factor-level combinations were conducted by use of Mann-Whitney-U test, depending on previous (overall) significance testing. In this explorative study, no adjustment of an alpha-error level was conducted.

\section{Results}

Baseline characteristics of patients were comparable among all groups (Table 1). About $6 \%$ of patients who received general anesthesia (GA\&FNB and GA\&LIA) compared to $3.5 \%$ of patients in the spinal anesthesia groups (SP\&EPI and SP\&LIA) suffered from chronic pain previously.

Pain exacerbation after surgery due to insufficient pain relief $(\mathrm{NRS}>7)$ with the current anesthetic technique led to another analgesic technique. In GA\&FNB, 4.9\% $(n=4)$ patients received a patient-controlled intravenous analgesia (PCIA) with an initial bolus of $4 \mathrm{mg}$ piritramide followed by an optional bolus of $2 \mathrm{mg}$ piritramide with a lockout of $10 \mathrm{~min}$. In the other groups, most anesthetic techniques with insufficient pain relief were converted to a secondary application of a FNB. These patients were excluded from outcome measurements. No analgesic technique-related or surgery-related complication occurred in any group within the first postoperative 7 days. At day of surgery, the demand for piritramide was significantly higher $(52 \%$ vs. $11 \% ; p<$
0.05) in groups with general anesthesia compared to groups with spinal anesthesia, while it was not significantly different between each other anymore at the first postoperative day $(p=0.77)$. All LIA patients received $160 \mathrm{ml}$ of the LIA injection with $16.4 \mathrm{mg} \pm 3.1$ (group GA\&LIA) and $15.7 \mathrm{mg} \pm 3.1$ (group SP\&LIA) dexamethasone, respectively.

\section{Pain}

The NRS scores (Fig. 1) at rest, although slightly increased at postoperative day $1(p=0.182)$, did not show any significant differences at any time $(p>0.05)$. The development of the NRS scores with activity was comparable among groups $(p>0.05)$; only both groups with spinal anesthesia demonstrated slightly but non-significantly increased pain values at the day of surgery $(p=0.132)$.

At the day of surgery as well as at postoperative days 1,2 and 3, the dose of hydromorphone was on average 42 to $58 \%$ lower in SP\&EPI compared to all other groups $(p<0.001$; Fig. 2). Additionally, at the day of surgery (OP) both catheter-based groups showed an on average $42 \%$ lower dose of hydromorphone compared to the LIA groups ( $<0.001$ ); afterwards, these differences were no longer significant $(p>0.05)$. In concordance with the indicated increase of the NRS scores at day 1, the dose of hydromorphone seemed to slightly increase, too, in order to gradually fall afterwards.

\section{Mobilization}

The grade of mobilization (0 to 6) revealed a gradual increase after surgery (Fig. 3). Hereby, all groups reached their base level of mobilization at day 6 . At the day of surgery and postoperative day 1, GA\&FNB presented a significantly lower grade of mobilization $(2.1 \pm 0.9$ and $3.4 \pm 0.8$, respectively) compared to SP\&LIA $(3.0 \pm 1.0$ and $3.8 \pm 0.7 ; p=0.003$ and $p=0.007$, respectively) and GA\&LIA ( $3.8 \pm 0.7 ; p=0.005$; only at day 1$)$. From postoperative day 2 on, no further significant differences among the groups could be detected $(p>0.05)$.

\section{Muscle strength}

The results of the muscle strength (Fig. 4) according to the British medical research council (M0/5-M5/5) showed a homogeneous increase after surgery with reaching strength against resistance (values $\geq 4$ ) in all groups from day 3 on. Compared to the LIA groups, GA\&FNB revealed statistically significant reduced muscle strength at day $1(3.4 \pm 0.9$ and $3.3 \pm 0.8$ vs. $2.7 \pm$ 0.8 each; $p<0.001$ and $p=0.001$, respectively) and day 2 $(3.8 \pm 0.8$ and $3.7 \pm 0.8$ vs. $3.3 \pm 0.9$ each; $p=0.011$ and $p$ $=0.039$, respectively); at day 3 only GA\&LIA showed higher muscle strength compared to GA\&FNB (4.0 \pm 0.6 vs. $3.7 \pm 0.7 ; p=0.019$ ). Additionally, the values of 


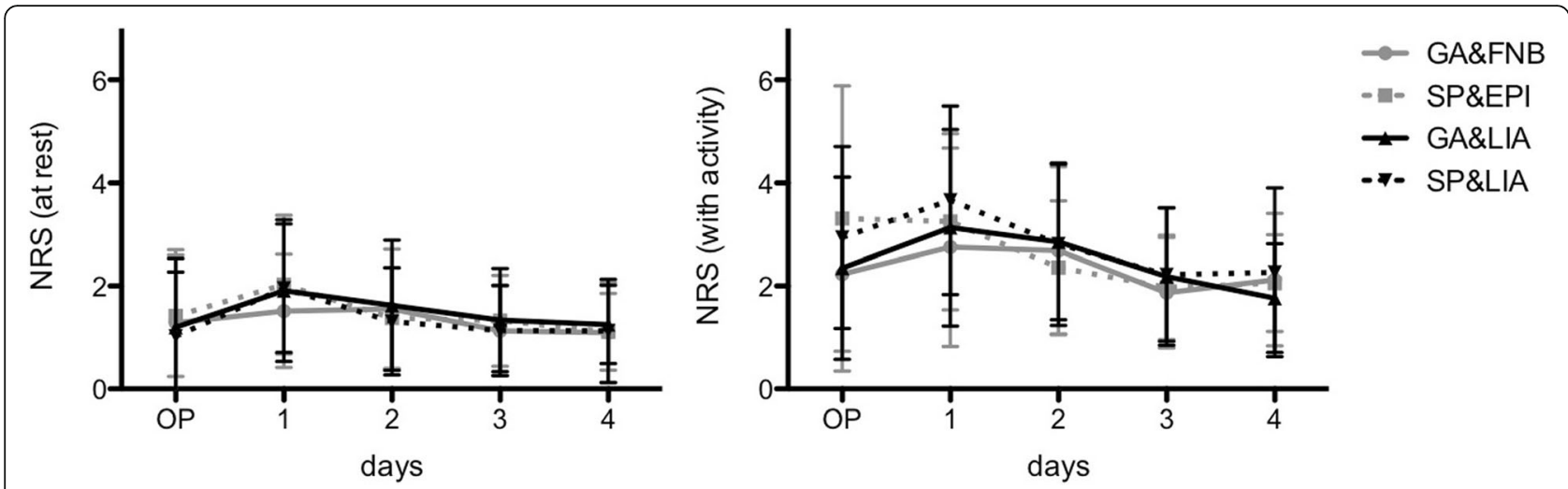

Fig. 1 Numeric Rating Scores at rest (left) and with activity (right) are presented for the day of surgery (OP) and postoperative days 1 to 4

SP\&EPI were significantly lower compared to GA\&LIA from day 1 to $3(2.9 \pm 0.9$ vs. $3.4 \pm 0.9, p=0.042 ; 3.3 \pm 1.0$ vs. $3.8 \pm 0.8, p=0.026$ and $3.6 \pm 0.8$ vs. $4.0 \pm 0.6, p=$ 0.024 , respectively).

\section{Range of motion}

The mean range of motion (flexion and extension of the knee joint) was comparable and not different among the groups $(p>0.05$, Fig. 5$)$ with the exception of SP\&LIA which demonstrated a higher flexion at day $1\left(56.1^{\circ} \pm\right.$ $\left.13.9^{\circ}\right)$ compared to GA\&FNB $\left(48.5^{\circ} \pm 13.7^{\circ} ; \mathrm{p}=0.001\right)$. From postoperative day 1 , flexion gradually increased while extension decreased. Considering all groups, $80^{\circ}$ of flexion was reached on day 6 .

\section{Discussion}

The aim of the LIA technique is to release the therapeutic effect by blocking pain conduction at its origin. Here, the distribution and the quantity of the injected local anesthetics are of great importance. Therefore, our injection was performed according to a standardized protocol to systematically reach every part of the knee joint's surrounding tissue. In an anatomic study, the anatomical spread of a LIA used in TKA was examined to identify the nerve structures reached by the injected fluid [19]. The results supported the positive clinical outcomes of the LIA techniques by visualization of good infiltration of the majority of nerves supplying the knee. Only in the lower popliteal fossa less solution could be detected. However, in particular, the posterior part of the knee is the most frequent area, where patients have pain postoperatively. By use of peripheral nerve blocks, this area is generally addressed by a SNB. Some clinical trials suggested that a SNB could improve postoperative analgesia when added to a FNB in patients undergoing TKA [5, 6]. To address this posterior knee pain, we regularly perform a FNB combined with a single shot SNB or we infiltrated the posterior articular capsule thoroughly with ropivacaine $(0.2 \%)$ in the LIA groups. Thereby, it is important to start with the posterior LIA injection before implantation of the inlay in order to have enough access to the posterior aspect.

In literature, most trials reported reduced pain and opioid requirements in the early $(<48 \mathrm{~h})$ postoperative

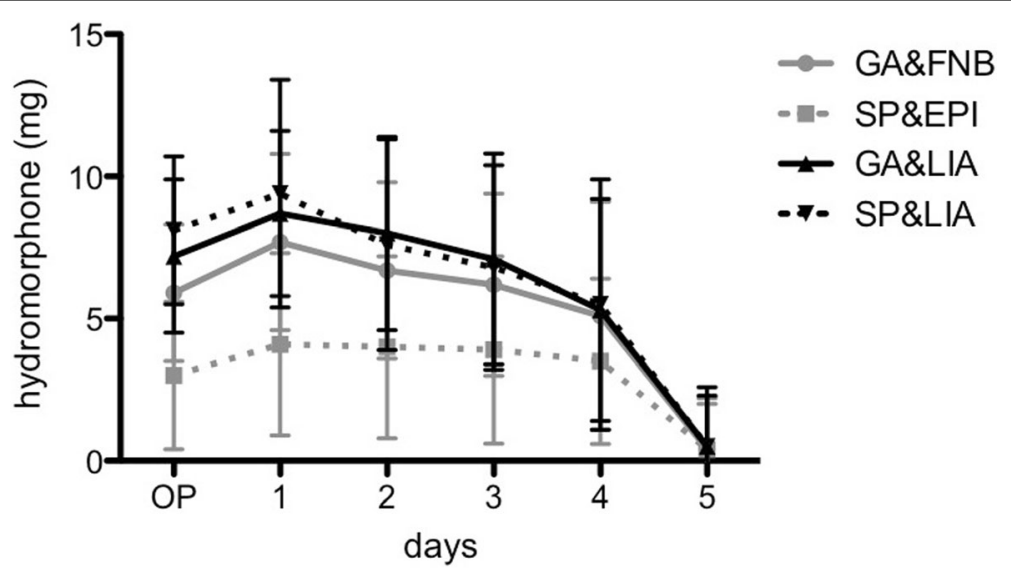

Fig. 2 The cumulative dose of hydromorphone (in $\mathrm{mg}$ ) for all groups at day of surgery until postoperative days 4 is shown 


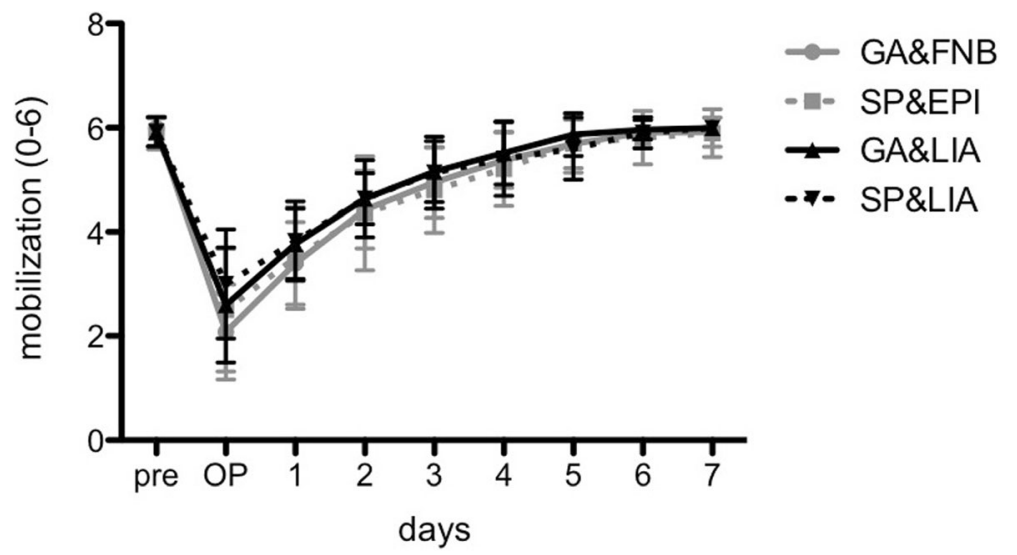

Fig. 3 The grade of mobilization (0 to 6) revealed a gradual increase after surgery until postoperative day 7

period with LIA compared with placebo or no injection [11-13]. In a meta-analysis, Keijsers et al. showed an average decrease in pain scores at rest of $12.3 \%$ and a decrease in opioid consumption of $14.8 \%$ compared to placebo at $24 \mathrm{~h}$ after surgery [20]. No significant differences were found between FNB (comparable with GA\&FNB) and epidural catheters (SP\&EPI) for TKA in terms of pain (at rest and with activity) in the early postoperative period [3, 7]. However, the side effects (e.g. hypotension or urinary retention) were higher with epidural catheters, which could not be detected within the first postoperative days in our study. Data comparing LIA with continuous epidural analgesia are limited and favor LIA over continuous epidural analgesia, particularly due the side-effects and early mobilization [16-18].

Compared to (peripheral) analgesic catheters, LIA generally achieves comparable results with regard to postoperative pain [21-23]. A recent systematic review and meta-analysis comparing FNB and LIA after total knee arthroplasty did not reveal any differences in morphine consumption and pain scores on postoperative day 1 [22].
These findings were in concordance with our results of GA\&FNB and GA\&LIA showing no significant differences in NRS scores at rest and with activity. However, in the very early postoperative period ( $\leq 6 \mathrm{~h}$ ), LIA seems to be able to achieve a better reduction in pain $[14,15]$. In our group, interestingly, at the day of surgery the catheter-based groups showed a significantly lower dose (on average $42 \%$ ) of hydromorphone compared to the LIA groups $(p<0.001)$. Furthermore, the spinal anesthesia group with an epidural catheter (SP\&EPI) revealed an up to $58 \%$ lower dose of hydromorphone from the day of surgery until day 3 compared to all other groups. Consistent with our results, Harsten et al. described a significantly reduced pain score with spinal anesthesia within the first $12 \mathrm{~h}$ in contrast to general anesthesia while both anesthetic procedures seem to generate the same overall pain ratings [24]. This is clinically relevant as a reduced opioid consumption consequently minimizes opioid-related adverse events. Furthermore, patients with a higher pain level preoperatively may rather benefit from spinal anesthesia and an epidural catheter.

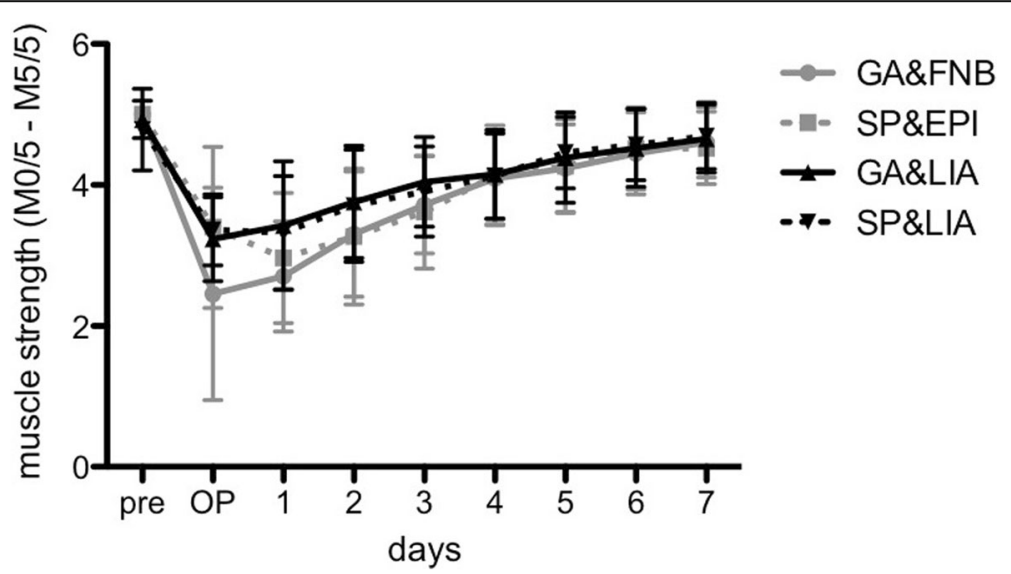

Fig. 4 The grade of muscle strength (M0/5 to M5/5) after surgery until postoperative day 7 is shown 


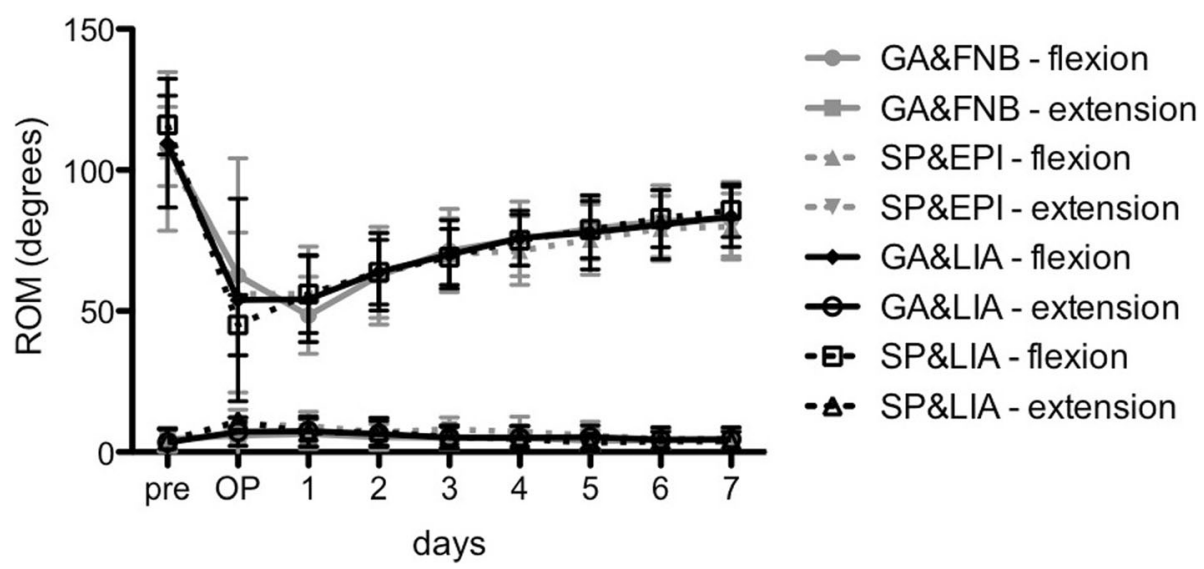

Fig. 5 Degrees of range of motion (flexion and extension) of all groups from preoperative day to postoperative day 7 are presented

But most mentioned studies just focused on pain relief and did not consider further functional aspects including mobilization, muscle strength or range of motion. In contrast to LIA groups, patients of GA\&FNB were less likely to be able to stand in front of their bed on the day of surgery or even start to ambulate at postoperative day 1 ; an effect attributed to possible residual muscular weakness from the two peripheral nerve blocks. These findings were supported by Safa et al., who also demonstrated a significantly minor mobilization in the FNB/ SNB group compared to LIA at day 1 [25]. However, there were no falls or short-term complication in the following days and functional recovery was comparable after 7 days among all groups. But the improved mobilization and significant higher muscle strength in the early postoperative period allow earlier intensive rehabilitation therapies and reduce especially in elderly patients the risks of a prolonged immediate postoperative immobilization (e.g. deep venous thrombosis, pulmonary infection). McDonald et al. also showed this trend in a randomized controlled trial comparing spinal anesthesia with epidural analgesia and LIA [23].

A common concern of the LIA technique is the potential toxic side effects, which might be elicited by a joint and tissue infiltration of local anesthetics like ropivacaine. Knudsen et al. defined the toxic threshold in arterial samples for unbound concentration of ropivacaine to be $0.56 \mu \mathrm{g} / \mathrm{ml}$ and for maximum total concentration to be $4.3 \mu \mathrm{g} / \mathrm{ml}$ [26]. A pharmacokinetic study with periarticular (single shot) infiltration of $400 \mathrm{mg}$ ropivacaine $(0.2 \%)$ after TKA revealed that the maximum unbound ropivacaine amounted to a concentration of $0.13 \mu \mathrm{g} / \mathrm{ml}$ and, therefore, remained far below the toxic threshold [27]. Although we did not analyze the plasma levels of ropivacaine in our study, we did not run the risk reaching the toxic threshold at any time by dose of $200 \mathrm{mg}$ ropivacaine $(0.2 \%)$.
There are some limitations that pertain to that study. The length of hospital stay was not a measured outcome of this study, however, all of our TKA patients followed a clinical pathway with standardized discharge criteria. This included the ability to ambulate and negotiate stairs with an assistive device, independent activities of daily living as well as knowledge of how to progress and continue an independent exercise program with an established plan for discharge physiotherapy. Furthermore, due to its retrospective design, the study was not blinded or randomized, which may have introduced reporting bias. The choice of anesthesia by the patient might also have induced some selection bias, although the group characteristics appeared to be identical among the four groups. Although it was a retrospective investigation, the strengths of the study include a large number of patients managed according to clear inclusion and exclusion criteria. The surgical and anesthetic procedures followed a consistent standard-treatment protocol in the same hospital by the same surgeons with extensive surgical experience in the treatment of total knee arthroplasties and its concomitant analgesic procedures.

\section{Conclusions}

In conclusion, the findings from this study suggest an advantage of LIA in the early postoperative periods in terms of mobilization and muscle strength. Range of motion was comparable among all groups. Pain control was also similar in all groups, while the use of rescue pain medication was significantly lower with SP\&EPI compared to all other groups within the first postoperative days. Thus, clinicians should consider the risk-to-benefit ratio for each case individually.

\section{Abbreviations}

FNB: Femoral nerve block; GA\&FNB: General anesthesia and femoral nerve block (+sciatic nerve block); GA\&LIA: General anesthesia and local infiltration analgesia; LIA: Local infiltration analgesia; NRS: Numeric rating scale; 
OP: Operation (day of surgery); PCIA: Patient-controlled intravenous analgesia; SNB: Sciatic nerve block; SP\&EPI: Spinal anesthesia and epidural catheter; SP\&LIA: Spinal anesthesia and local infiltration analgesia; TKA: Total knee arthroplasty

\section{Acknowledgments}

The authors thank the research assistants (Steffen Klingbeil and Dr. Isabella Klöpfer-Krämer), Christa Gerhäußer and the whole (pain) nursing staff as well as the physiotherapy department for their support.

\section{Availability of data and materials}

The datasets used and/or analyzed during the current study are available from the corresponding author on reasonable request.

\section{Authors' contributions}

MTB, JF, PA and WR drafted the manuscript, contributed to the acquisition of data, analysis, and interpretation of data. PA helped with the statistical analysis of the data. MTB, WL and CF participated in conception, design and coordination. WR and VB supervised the whole study and helped to finalize the manuscript. All authors read and approved the final manuscript.

\section{Ethics approval and consent to participate}

This study adhered to the tenets of the Helsinki Declaration and its later amendments. It was conducted according to ICMJE guidelines. Written consent was obtained from all participants for the surgical and anesthetic procedures; further consent for retrospective analysis of the data was waived by the Ethics Committee of the Bavarian State Chamber of Physicians (ID: 2017-109).

\section{Consent for publication}

Not applicable.

\section{Competing interests}

The authors declare that they have no competing interests.

\section{Publisher's Note}

Springer Nature remains neutral with regard to jurisdictional claims in published maps and institutional affiliations.

\section{Author details}

${ }^{1}$ endogap, Joint Replacement Institute, Garmisch-Partenkirchen Medical Center, Auenstr. 6, 82467 Garmisch-Partenkirchen, Germany. ${ }^{2}$ Department of Trauma Surgery, BG Trauma Center Murnau, Prof.-Küntscher Str. 8, 82418 Murnau, Germany. ${ }^{3}$ Department of Anesthesiology and Intensive Care, Garmisch-Partenkirchen Medical Center, Auenstr. 6, 82467 Garmisch-Partenkirchen, Germany. ${ }^{4}$ Institute of Biomechanics, BG Trauma Center Murnau, Prof.-Küntscher Str. 8, 82418 Murnau, Germany. ${ }^{5}$ Institute of Biomechanics, Paracelsus Medical University, Strubergasse 21, 5020 Salzburg, Austria.

Received: 3 January 2018 Accepted: 24 June 2018

Published online: 18 July 2018

\section{References}

1. Bauer MC, Pogatzki-Zahn EM, Zahn PK. Regional analgesia techniques for total knee replacement. Curr Opin Anaesthesiol. 2014;27(5):501-6.

2. Karlsen AP, Wetterslev M, Hansen SE, Hansen MS, Mathiesen O, Dahl JB. Postoperative pain treatment after total knee arthroplasty: a systematic review. PLoS One. 2017;12(3):e0173107.

3. Chan EY, Fransen M, Parker DA, Assam PN, Chua N. Femoral nerve blocks for acute postoperative pain after knee replacement surgery. Cochrane Database Syst Rev. 2014;5:CD009941.

4. Morin AM, Kratz CD, Eberhart LH, Dinges G, Heider E, Schwarz N, Eisenhardt G, Geldner G, Wulf H. Postoperative analgesia and functional recovery after total-knee replacement: comparison of a continuous posterior lumbar plexus (psoas compartment) block, a continuous femoral nerve block, and the combination of a continuous femoral and sciatic nerve block. Reg Anesth Pain Med. 2005;30(5):434-45.

5. Cook P, Stevens J, Gaudron C. Comparing the effects of femoral nerve block versus femoral and sciatic nerve block on pain and opiate consumption after total knee arthroplasty. J Arthroplast. 2003;18(5):583-6.
6. Weber A, Fournier R, Van Gessel E, Gamulin Z. Sciatic nerve block and the improvement of femoral nerve block analgesia after total knee replacement. Eur J Anaesthesiol. 2002;19(11):834-6.

7. Fowler SJ, Symons J, Sabato S, Myles PS. Epidural analgesia compared with peripheral nerve blockade after major knee surgery: a systematic review and meta-analysis of randomized trials. Br J Anaesth. 2008;100(2):154-64.

8. Popping DM, Zahn PK, Van Aken HK, Dasch B, Boche R, Pogatzki-Zahn EM. Effectiveness and safety of postoperative pain management: a survey of 18 925 consecutive patients between 1998 and 2006 (2nd revision): a database analysis of prospectively raised data. Br J Anaesth. 2008;101(6):832-40.

9. Kerr DR, Kohan L. Local infiltration analgesia: a technique for the control of acute postoperative pain following knee and hip surgery: a case study of 325 patients. Acta Orthop. 2008;79(2):174-83.

10. Ganapathy S. Wound/intra-articular infiltration or peripheral nerve blocks for orthopedic joint surgery: efficacy and safety issues. Curr Opin Anaesthesiol. 2012;25(5):615-20.

11. Andersen LO, Husted H, Kristensen BB, Otte KS, Gaarn-Larsen L, Kehlet H. Analgesic efficacy of subcutaneous local anaesthetic wound infiltration in bilateral knee arthroplasty: a randomised, placebo-controlled, double-blind trial. Acta Anaesthesiol Scand. 2010;54(5):543-8.

12. Niemelainen $M$, Kalliovalkama J, Aho AJ, Moilanen T, Eskelinen A. Single periarticular local infiltration analgesia reduces opiate consumption until 48 hours after total knee arthroplasty. A randomized placebo-controlled trial involving 56 patients. Acta Orthop. 2014;85(6):614-9.

13. Essving P, Axelsson K, Kjellberg J, Wallgren O, Gupta A, Lundin A. Reduced morphine consumption and pain intensity with local infiltration analgesia (LIA) following total knee arthroplasty. Acta Orthop. 2010;81(3):354-60.

14. Yun XD, Yin XL, Jiang J, Teng YJ, Dong HT, An LP, Xia YY. Local infiltration analgesia versus femoral nerve block in total knee arthroplasty: a metaanalysis. Orthop Traumatol Surg Res. 2015;101(5):565-9.

15. Moghtadaei M, Farahini H, Faiz SH, Mokarami F, Safari S. Pain Management for Total Knee Arthroplasty: single-injection femoral nerve block versus local infiltration analgesia. Iran Red Crescent Med J. 2014;16(1):e13247.

16. Spreng UJ, Dahl V, Hjall A, Fagerland MW, Raeder J. High-volume local infiltration analgesia combined with intravenous or local ketorolac +morphine compared with epidural analgesia after total knee arthroplasty. Br J Anaesth. 2010;105(5):675-82.

17. Andersen KV, Bak M, Christensen BV, Harazuk J, Pedersen NA, Soballe K. A randomized, controlled trial comparing local infiltration analgesia with epidural infusion for total knee arthroplasty. Acta Orthop. 2010;81(5):606-10.

18. Binici Bedir E, Kurtulmus T, Basyigit S, Bakir U, Saglam N, Saka G. A comparison of epidural analgesia and local infiltration analgesia methods in pain control following total knee arthroplasty. Acta Orthop Traumatol Turc. 2014:48(1):73-9.

19. Quinn M, Deakin AH, McDonald DA, Cunningham IK, Payne AP, Picard F. An anatomic study of local infiltration analgesia in total knee arthroplasty. Knee. 2013;20(5):319-23.

20. Keijsers $R$, van Delft R, van den Bekerom MP, de Vries DC, Brohet RM, Nolte PA. Local infiltration analgesia following total knee arthroplasty: effect on post-operative pain and opioid consumption-a meta-analysis. Knee Surg Sports Traumatol Arthrosc. 2015;23(7):1956-63.

21. Emerson RH Jr, Barrington JW, Olugbode O, Lovald S, Watson H, Ong K. Femoral nerve block versus long-acting wound infiltration in Total knee arthroplasty. Orthopedics. 2016;39(3):e449-55.

22. Albrecht E, Guyen O, Jacot-Guillarmod A, Kirkham KR. The analgesic efficacy of local infiltration analgesia vs femoral nerve block after total knee arthroplasty: a systematic review and meta-analysis. Br J Anaesth. 2016; 116(5):597-609.

23. McDonald DA, Deakin AH, Ellis BM, Robb Y, Howe TE, Kinninmonth AW, Scott NB. The technique of delivery of peri-operative analgesia does not affect the rehabilitation or outcomes following total knee arthroplasty. Bone Joint J. 2016;98-B(9):1189-96.

24. Harsten A, Hjartarson H, Werner MU, Toksvig-Larsen S. General anaesthesia with multimodal principles versus intrathecal analgesia with conventional principles in total knee arthroplasty: a consecutive randomized study. J Clin Med Res. 2013;5(1):42-8.

25. Safa B, Gollish J, Haslam L, McCartney CJ. Comparing the effects of single shot sciatic nerve block versus posterior capsule local anesthetic infiltration on analgesia and functional outcome after total knee arthroplasty: a prospective, randomized, double-blinded, controlled trial. J Arthroplasty. 2014;29(6):1149-53. 
26. Knudsen K, Beckman Suurkula M, Blomberg S, Sjovall J, Edvardsson N. Central nervous and cardiovascular effects of i.V. Infusions of ropivacaine, bupivacaine and placebo in volunteers. Br J Anaesth. 1997;78(5):507-14.

27. Fenten MG, Bakker SM, Touw DJ, van den Bemt BJ, Scheffer GJ, Heesterbeek PJ, Stienstra R. Pharmacokinetics of $400 \mathrm{mg}$ ropivacaine after periarticular local infiltration analgesia for total knee arthroplasty. Acta Anaesthesio Scand. 2017;61(3):338-45.

Ready to submit your research? Choose BMC and benefit from:

- fast, convenient online submission

- thorough peer review by experienced researchers in your field

- rapid publication on acceptance

- support for research data, including large and complex data types

- gold Open Access which fosters wider collaboration and increased citations

- maximum visibility for your research: over $100 \mathrm{M}$ website views per year 